\title{
Phenotypic Expression of Methicillin Resistance in Nosocomial Staphylococcus aureus
}

Dear Editor,

Methicillin resistant Staphylococcus aureus (MRSA) is an important nosocomial pathogen worldwide. It can also cause community acquired infections. Early diagnosis of MRSA infection is important to start correct treatment. The MRSA clinical isolates can be grouped into four phenotypic expression classes by population analysis profile. ${ }^{[1]}$ In the heterogeneous phenotypes only a small proportion of the cells express resistance at high level whereas the majority are susceptible. The occurrence of heterogeneous resistance among MRSA contributes to their misidentification. The objective of the present study was to analyse methicillin resistance in nosocomial $S$. aureus by population analysis profile.
A total of 210 strains of $S$. aureus isolated from clinical specimen were used in the study. The isolation and identification of $S$. aureus was performed at the Department of Microbiology, Kasturba Medical College, Mangalore. MRSA was identified by disk diffusion, agar screen and agar dilution method. ${ }^{[2-4]}$ For disk diffusion, lawn culture of bacteria was prepared on Mueller-Hinton agar, $1 \mu \mathrm{g}$ oxacillin disk was applied and the results were read after 24 hours incubation at $35^{\circ} \mathrm{C}$. In agar screen method, bacteria were grown in nutrient broth at $37^{\circ} \mathrm{C}$ for 24 hours and bacterial cultures $(100 \mu \mathrm{L})$ were spot inoculated on Mueller-Hinton agar supplemented with $4 \% \mathrm{NaCl}$ and oxacillin $6 \mu \mathrm{g} / \mathrm{mL}$. Resistance was confirmed by the growth of bacteria after incubation at $37^{\circ} \mathrm{C}$ for 24 hours. Minimum 


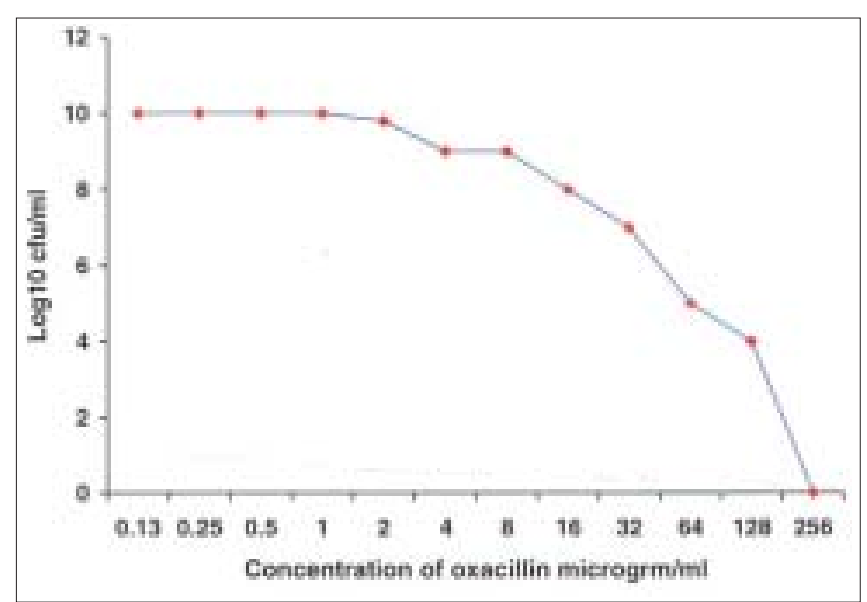

Figure: Population analysis profile of one strain of MRSA showing number of colonies on Mueller-Hinton agar plate with different concentrations of oxacillin

inhibitory concentration (MIC) of oxacillin to S. aureus was determined by agar dilution method. $S$. aureus strains with MIC of oxacillin $\geq 4 \mu \mathrm{g} / \mathrm{mL}$ were considered MRSA $^{[3,4]}$ Population analysis profile (PAP) was determined using standard method. ${ }^{[11]}$ Overnight bacterial broth cultures (bacterial concentration $10^{9}-10^{10} \mathrm{cfu} / \mathrm{mL}$ ) were plated at different dilutions on Mueller-Hinton agar containing different concentrations $(0.125-512 \mu \mathrm{g} / \mathrm{mL})$ of oxacillin and on oxacillin free medium (growth control). The plates were incubated at $37^{\circ} \mathrm{C}$ for 48 hours and the number of colonies on each plate was counted.

Of 210 isolates of S. aureus, 69(33\%) were MRSA by agar screen method and $59(28 \%)$ by disk diffusion technique. This is indicative of the superiority of agar screen method for the detection of MRSA. The MICs of oxacillin to $S$. aureus. were $0.125,0.25,0.5,2,4,8,16,32$, $64,128,256$ and $512 \mu \mathrm{g} / \mathrm{mL}$ in $53,38,27,23,18,4,3,17$, $19,4,1$ and 3 strains respectively. The present study clearly showed the unreliability of disk diffusion technique to detect MRSA. $\mathrm{NaCl}$ and low temperature $\left(35^{\circ} \mathrm{C}\right)$ usually favour the expression of chromosomally mediated heterogeneous methicillin resistance in $S$. aureus. ${ }^{[1,5]}$ The use of higher bacterial density and presence of $\mathrm{NaCl}$ in the medium may help in better detection of MRSA by agar screen method. MRSA clinical isolates can be divided into four phenotypic expression classes (1-4) by population analysis profile.
[3] In MRSA class 1 phenotype, majority of the bacteria are methicillin sensitive (MIC $1.5-3 \mu \mathrm{g} / \mathrm{mL}$ ) and minority $\left(10^{-8}-10^{-6}\right)$ have higher MIC values $(50-100 \mu \mathrm{g} / \mathrm{mL})$. In class 2 phenotype, only $10^{-5}-10^{-4}$ cells have higher MIC values $(200-400 \mu \mathrm{g} / \mathrm{mL})$. MRSA classes 3 and 4 show homogeneous resistance with methicillin MIC usually $>400$ $\mu \mathrm{g} / \mathrm{mL}$. In the present study three isolates showed oxacillin MIC $512 \mu \mathrm{g} / \mathrm{mL}$. The PAP could show heterogeneous methicillin/oxacillin resistance in 40 isolates. PAP of one strain of $S$. aureus is shown in the figure.

The PAP of MRSA strains showed that heterogeneous oxacillin/methicillin resistance that occurs may not be detected if one uses the routine disk diffusion test. This will result in an error (characterization of resistant isolates as susceptible) while reporting. The agar screen and dilution methods should be used for the reliable detection of MRSA.

\section{References}

1. Thomasz A, Nachman S, Leaf H. Stable classes of phenotypic expression in methicillin - resistance isolates of staphylococci. Antimicrob Agents Chemother 1991;35:124-9.

2. Swenson JM, Hindler JA, Peterson LR. Special phenotypic methods for the detection of antibacterial resistance. In: Murray PR, Barn EJ, Pfaller MA, Tenover FE, Yolken RH, editors. Manual of clinical microbiology, $7^{\text {th }}$ ed. Washington: ASM Press; 1999. p. 264-82.

3. Clinical and Laboratory Standards Institute: Methods of dilution antimicrobial susceptibility testing for bacteria that grow aerobically: Approved standard M7-A7, ed 7, Wayne, Pa 2006, CLSI.

4. Laboratory detection of oxacillin/methicillin resistant Staphylococcus aureus. Available from: http://www.cdc.gov/ ncidod/dhap/arlabmrsa.html. [last 2005 Feb 2].

5. Figueiredo AM, Ha E, Kreisworth BN, de Lencastre $\mathrm{H}$, Noel GJ, Senterfit L, et al. In Vivo stability of heterogeneous expression classes in clinical isolates of methicillin resistant staphylococci. J Infect Dis 1991;164:883-7.

*GK Bhat, LS Jathana, A Kumar

Department of Microbiology, Kasturba Medical College, Mangalore-575 001, Karnataka, India

*Corresponding author (email: <gkbhat61@yahoo.co.in>)

Received: 10-01-08

Accepted: 21-02-08 